\title{
PSO Based Short-Term Hydrothermal Scheduling with Prohibited Discharge Zones
}

\author{
G.Sreenivasan \\ Associate Professor, \\ Dept. of Electrical Engineering, \\ Intell Engineering College, \\ Anantapur, AP, India.
}

\author{
Dr. C.H.Saibabu, \\ Professor, \\ Dept. of Electrical Engineering, \\ JNTU Kakinada, Kakinada, \\ AP, India
}

\author{
Dr.S.Sivanagaraju \\ Associate Professor, \\ Dept. of Electrical Engineering, \\ JNTU Kakinada, Kakinada, \\ AP, India.
}

\begin{abstract}
This paper presents a new approach to determine the optimal hourly schedule of power generation in a hydrothermal power system using PSO technique.. The simulation results reveal that the proposed PSO approach appears to be the powerful in terms of convergence speed, computational time and minimum fuel cost.
\end{abstract}

Keywords- Hydrothermal scheduling; Particle Swarm Optimization; Valve - point loading effect; Prohibited Discharge Zones.

\section{INTRODUCTION}

The optimal scheduling of generation in a hydrothermal system involves the allocation of generation among the hydroelectric and thermal plants so as to minimize the total operation costs of thermal plants while satisfying the various constraints on the hydraulic and power system network. In Short-term scheduling it is normally assumed that the largest dam levels at the end of the scheduling period have been set a medium term scheduling process that takes into account longer term river inflow modeling and load predictions. The short term scheduler than allocates this water (Power) to the various time intervals in an effort to minimize thermal generation costs while attempting to satisfy the various unit and reservoir constraints.

The main constraints include the time coupling effect of the hydro sub problem, where the water flow in an earlier time intervals affects the discharge capability at a later period of time, the time varying system long demand, the cascade nature of the hydraulic network, the varying hourly reservoir inflows, the physical limitations on the reservoir storage and turbine flow rate and loading limits of both thermal and hydro plants. Further constraints could be depending on the particular requirements of a given power system, such as the need to satisfy activities including, flood control, irrigation, fishing, water supply etc., The hydrothermal scheduling problem has been the subject of intensive investigation for several decades now.

Most of the methods that have been used to solve the hydrothermal co-ordination problem make a number of simplifying assumptions in order to make the optimization problem more tractable.

The performances of different stochastic techniques have been studied in the literature [6-14]. Though stochastic techniques have been proved to be very efficient and having faster performances than the conventional methods, there are some limitations in the goodness of the solutions to the problem that are obtained in [13]. From the literature it is found that particle swarm optimization technique has the fastest convergence rate to the global solution amongst all algorithms and has highest potential of finding more nearly global solutions to hydrothermal co-ordination problems [13]. Early works on PSO have shown the rich promise of emergence of a relatively simple optimization technique this is easier to understand compared to other evolutionary computation techniques presently available eg. Genetic algorithm and evolutionary programming.

Another advantage of PSO can be the possibility of tuning smaller number of free, tunable parameters to arrive at the desired goal. The PSO technique has been applied to various fields of power system optimization. Yu et al applied PSO technique to solve short-term hydrothermal scheduling [16] with an equivalent thermal unit having smooth cost functions connected to hydel systems. Here the constraints were handled by penalty function method [16]. But the performance of PSO to Short-term hydrothermal scheduling for interconnected individual thermal units with non-smooth cost function has not been tested yet.

In this paper PSO method is proposed for short-term optimal scheduling of generation in a hydrothermal system which involves the allocation of generation among the multireservoirs cascaded hydro plants and thermal plants with prohibited discharge zones and valve point loading effects so as to minimize the fuel cost of equivalent thermal plant while satisfying the various constraints on the hydraulic and power system network.

To validate the PSO based hydrothermal scheduling algorithm, the developed algorithm has been illustrated for a test system [11]. The same problem has been solved by GA and the results are compared. The performance of the proposed method is found to be quite encouraging as compared with other methods.

\section{Problem Statement}

NOMENCLATURE :

C Composite Cost function 


\begin{tabular}{|c|c|}
\hline$C_{i}$ & fuel cost of $i$ \\
\hline$P_{G T j M}$ & $\begin{array}{l}\text { Output power of } i^{\text {th }} \text { thermal } \\
\text { unit at time 'm} \text { ' }\end{array}$ \\
\hline$P_{G H j M}$ & $\begin{array}{l}\text { Output power of } j^{t h} \\
\text { hydro unit at time ' } \mathrm{m} \text { ' }\end{array}$ \\
\hline$P_{G T i}^{\min }, P_{G T i}^{\max }$ & $\begin{array}{l}\text { Lower and Upper } \\
\text { generation limits for } i^{\text {th }} \\
\text { thermal units }\end{array}$ \\
\hline$a_{i}, b_{i}, c_{i}$ and $d_{i}$ & $\begin{array}{l}e_{i} \text {-cost curve co - efficients } \\
\text { of } i^{\text {th }} \text { thermal unit }\end{array}$ \\
\hline$P_{D m}$ & Load demand at time 'm' \\
\hline$P_{G H j}{ }^{\min }, P_{G H j}^{\max }$ & $\begin{array}{l}\text { Lower and Upper generation } \\
\text { limits for } i^{t h} \text { thermal unit }\end{array}$ \\
\hline$Q_{H j m}$ & $\begin{array}{l}\text { Water discharge rate of ith } \\
\text { reservoir at time ' } \mathrm{m} \text { ' }\end{array}$ \\
\hline$V_{H J m}$, & $\begin{array}{l}\text { Storage volume of } j^{\text {th }} \\
\text { reservoir at time ' } \mathrm{m} \text { ' }\end{array}$ \\
\hline$Q_{H J}^{\min }, Q_{H J}^{\max }$ & $\begin{array}{l}\text { Minimum and Maximum } \\
\text { water discharge rate of } j^{\text {th }} \\
\text { reservoir }\end{array}$ \\
\hline$V_{H J}^{\min }, V_{H J}^{\max }$ & $\begin{array}{l}\text { Minimum and Maximum } \\
\text { Storage volume of } j^{\text {th }} \\
\text { reservoir }\end{array}$ \\
\hline$P_{L m}$ & $\begin{array}{l}\text { Total transmission line losses } \\
\text { at time ' } m \text { ' }\end{array}$ \\
\hline$C_{l j}, C_{2 j}, C_{3 j}, C_{4 j}$ & $\begin{array}{l}C_{5 j}, C_{6 j}, \\
\text { Power generation co - } \\
\text { efficients of } j^{\text {th }} \text { hydro unit }\end{array}$ \\
\hline$I_{H j m}$ & $\begin{array}{l}\text { Inflow rate of } j^{\text {th }} \text { reservoir at } \\
\text { time ' } \mathrm{m} \text { ' }\end{array}$ \\
\hline$S_{H j m}$ & $\begin{array}{l}\text { Spillage of } j^{\text {th }} \text { reservoir at time } \\
\text { ' } \mathrm{m} \text { ' }\end{array}$ \\
\hline$T_{l j}$ & $\begin{array}{l}\text { Water transport delay from } \\
\text { reservoir } 1 \text { to } j\end{array}$ \\
\hline$R_{u j}$ & $\begin{array}{l}\text { Set of upstream units directly } \\
\text { above } j^{\text {th }} \text { hydro plant }\end{array}$ \\
\hline$N_{G T}$ & $\begin{array}{l}\text { Number of thermal generating } \\
\text { units }\end{array}$ \\
\hline$N_{G H}$ & $\begin{array}{l}\text { Number of hydro generating } \\
\text { units }\end{array}$ \\
\hline$m, M$ & Time index, scheduling period \\
\hline & $\begin{array}{l}\text { Initial storage volume of } j^{\text {th }} \\
\text { Reservoir }\end{array}$ \\
\hline$V_{H j}^{\text {end }}$ & $\begin{array}{l}\text { Final storage volume of } j^{\text {th }} \\
\text { Reservoir }\end{array}$ \\
\hline
\end{tabular}

\section{Mathematical Formulation}

Hydrothermal Scheduling involves the optimization of a problem with a non-linear objective function, with a mixture of linear, non-linear and dynamic network flow constraints. The problem difficulty is compounded by a number of practical considerations and unless several simplifying assumption are made, this problem is difficult to solve for practical power systems as shown in fig 1 .

Due to Zero incremental cost of hydro generating units, the prime objective of the short-term hydrothermal scheduling problem becomes to minimize the fuel cost of thermal plants, while making use of the availability of hydropower as much as possible, such that the load demands $\mathrm{P}_{\mathrm{D}}$ supplied from hydro plants and a thermal plant in the intervals of the generation scheduling horizon can be met and simultaneously, all the equality and inequality operation constraints are satisfied.

The objective function and associated constraints of the Hydrothermal scheduling problem are formulated as follows.

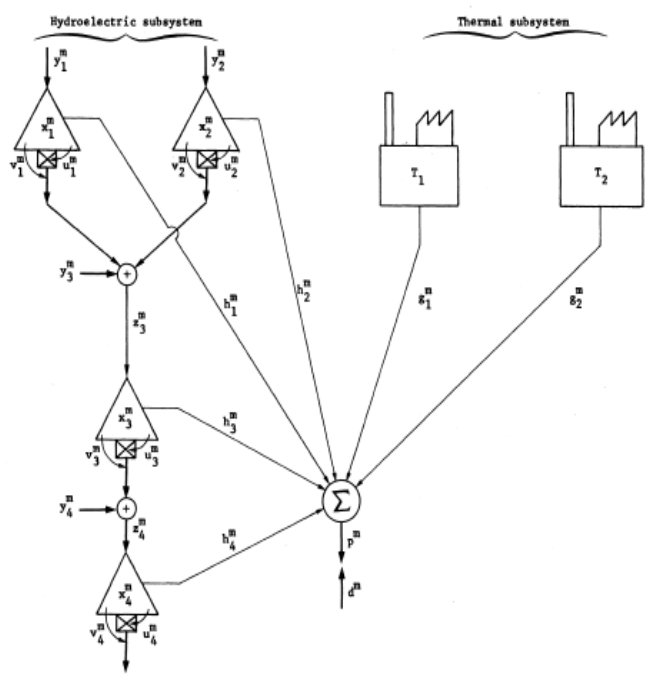

Fig.1 Practical Hydrothermal Power system Network

\section{A. Objective Function}

The total fuel cost for running the thermal system to meet the load demand in scheduling horizon is given by $\mathrm{C}$. The objective function is expressed mathematically, as

$$
\text { Minimize } \quad \mathrm{C}=\sum_{i=1}^{N_{G T}} C_{i}\left(P_{G T i}\right)
$$

When considering valve-point effects, the fuel cost function of each thermal generating unit is expressed as the sum of a quadratic and a sinusoidal function. The total fuel cost in-terms of real power output can be expressed as :

$$
\begin{aligned}
C= & \sum_{m=1}^{M} \sum_{i=1}^{N_{G T}}\left[a_{i}+b i P_{\text {GTim }}+c_{i} P_{\text {GTim }}{ }^{2}\right. \\
& \left.+\left|\mathrm{d}_{\mathrm{i}} \sin \left\{\mathrm{e}_{\mathrm{i}}\left(\mathrm{P}_{\mathrm{GTi}^{m i n}}{ }^{\min } \mathrm{P}_{\mathrm{GTim}}\right)\right\}\right|\right]
\end{aligned}
$$

subject to a number of unit and power system network constraints.

\section{B. constraints}

This non-linear constrained hydrothermal scheduling optimization problem is subjected to a variety of constraints depending upon practical implications like the varying system load demand, the time coupling effect of hydro subsystem, the cascading nature of the hydraulic network, the time varying hourly reservoir inflows, thermal plant and hydro plant operating limits, system losses, reservoir storage limits, water 
discharge rate limits, hydraulic continuity constraints and initial and final reservoir storage limits. These constraints are discussed below.

\section{1) Power balance constraints(Demand Constraints)}

This constraint is based on the principle of equilibrium between the total active power generation from the hydro and thermal plants and the total system demand plus the system losses in each time interval of scheduling ' $\mathrm{m}$ '

$$
\sum_{i=1}^{N_{G T}} P_{G T i m} P_{i m}+\sum_{j=1}^{N_{G H}} P_{G H j m}=P_{\text {Dm }}+P_{\text {lossm }} m \in M
$$

\section{2) Thermal Generator Constraints}

The operating limit of equivalent thermal generator has a lower and upper bound so that it lies in between these bounds.

$P_{G T}{ }^{\text {min }} \leq P_{G T i m} \leq P_{G i}^{\text {max }}, \quad m \in M$

3) Hydro Generator Constraints

The operating limit of hydro plant must lie in between its upper and lower bounds.

$$
P_{G H j}^{\text {min }} \leq P_{G H j m} \leq P_{G H j}{ }^{\max }, \quad j \in N_{G H}, m \in M
$$

\section{HYDRAULIC NETWORK CONSTRAINTS}

The hydraulic operational constraints comprise the water balance (Continuity) equations for each hydro unit (System) as well as the bounds on reservoir storage and release targets.

These bounds are determined by the physical reservoir and plant limitations as well as the multipurpose requirements of the hydro system. These constraints include :

\section{1) Reservoir Capacity Constraints}

The operating volume of reservoir storage limit must lie in between the minimum and maximum capacity limits.

$$
V_{H j}{ }^{\text {min }} \leq V_{H j m} \leq V_{H j}^{\text {max }}, \quad j \in N_{H}, m \in M
$$

\section{2) The Water Discharge Constraints}

The variable net head operation is considered and the physical limitation of water discharge of turbine, $\mathrm{Q}_{\mathrm{Hjm}}$, Must lie in between maximum and minimum operating limits, as given by

$$
Q_{H j}{ }^{\text {min }} \leq Q_{H j m} \leq Q_{H j}{ }^{\text {max }}, j \in N_{H}, \quad m \in M
$$

3) Reservoir end conditions

The desired volume of water to be discharged by each reservoir over the scheduling period,

$$
\begin{aligned}
& \left.V_{H j m}\right|^{m=0}=V_{H j}^{\text {begin }} \\
& \left.V_{H j m}\right|^{m=m}=V_{H j}^{\text {end }} \quad j \in N_{H} \\
& \text { 4) Hydraulic Continuity Equation Constraint }
\end{aligned}
$$

The storage reservoir volume limits are expressed with given initial and final volumes as

$$
\begin{gathered}
V_{H j m H}=V_{H j m}+\sum_{u=1}^{\mathrm{Ru}}\left[Q_{H u}\left(m-\tau_{l j}\right)+S_{u}\left(\mathrm{~m}-\tau_{\mathrm{lj}}\right)\right]-Q_{H j} \\
(m+1)-S_{j(m+1)}+\gamma_{j(m+1)} \text { for } j \in N_{H}, m \in M
\end{gathered}
$$

Where $\tau_{\mathrm{jj}}$ is the water delay time between reservoir $l$ and its upstream $u$ at interval' $m$ '. 'j'.

$\mathrm{R}_{\mathrm{u}}$ is the set of upstream units directly above the hydro plant

\section{5) Power Generation Characteristics}

The Power generated from a hydro plant is related to the reservoir characteristics as well as the water discharge rate. A number of models have been used to represent this relationship. In general, the hydro generator power output is a function of the net hydraulic head, $\mathrm{H}$, reservoir volume, $\mathrm{V}_{\mathrm{H}}$, and the rate of water discharge, $\mathrm{Q}_{\mathrm{H}}$,

$$
\mathrm{P}_{\mathrm{GHjm}}=f\left(\mathrm{Q}_{\mathrm{Hjm}}, \mathrm{V}_{\mathrm{Hjm}}\right) \text { and } \mathrm{V}_{\mathrm{Hjm}}=f\left(\mathrm{H}_{\mathrm{jm}}\right)
$$

The model can also be written in-terms of reservoir volume instead of the reservoir net head, and a frequently used functional is

$$
\begin{array}{r}
\mathrm{P}_{\mathrm{GHjm}}=\mathrm{C}_{1 \mathrm{j}} \mathrm{V}_{\mathrm{Hjm}}^{2}+\mathrm{C}_{2 \mathrm{j}} \mathrm{Q}_{\mathrm{Hjm}}^{2}+\mathrm{C}_{3 \mathrm{j}} \mathrm{V}_{\mathrm{Hjm}} \mathrm{Q}_{\mathrm{Hjm}}+\mathrm{C}_{4 \mathrm{j}} \mathrm{V}_{\mathrm{Hjm}}+\mathrm{C}_{5 \mathrm{j}} \mathrm{Q}_{\mathrm{Hjm}}+ \\
\mathrm{C}_{6 \mathrm{j}}, j \in N_{H}, m \in M(11)
\end{array}
$$

Net head variation can only be ignored for relatively large reservoirs, in which case power generation is solely dependent on the water discharge. In setting the generation levels of the thermal plants, a quadratic cost function is used to model the fuel input power output characteristic of thermal units.

\section{PARTIClE SWARM OPTIMIZATION}

Particle swarm optimization is one of the most recent developments in the category of combinatorial metaheuristic optimizations. This method has been developed under the scope of artificial life where PSO is inspired by the natural phenomenon of fish schooling or bird flocking. PSO is basically based on the fact that in quest of reaching the optimum solution in a multi-dimensional space, a population of particles is created whose present coordinate determines the cost function to be minimized. After each iteration the new velocity and hence the new position of each particle is updated on the basis of a summated influence of each particle's present velocity, distance of the particle from its own best performance, achieve so far during the search process and the distance of the particle from the leading particle, i.e. the particle which at present is globally the best particle producing till now the best performance i.e. minimum of the cost function achieved so far.

Let $\mathrm{x}$ and $\mathrm{v}$ denote a particle position and its corresponding velocity in a search space, respectively. Therefore, the $i^{\text {th }}$ particle is represented as $\mathrm{x}_{\mathrm{i}}=\left(\mathrm{x}_{\mathrm{i} 1}, \mathrm{x}_{\mathrm{i} 2}, \ldots, \mathrm{x}_{\mathrm{id}}\right)$ in the ' $\mathrm{d}$ ' dimensional space. The best previous position of the $i^{\text {th }}$ particles recorded and represented as pbest $\mathrm{i}_{\mathrm{i}}=\left(\mathrm{pbest}_{\mathrm{i} 1}\right.$, pbest $_{\mathrm{i} 2}$, . . ., pbest $\left.{ }_{i d}\right)$. The index of the best particle among all the particles in the group is represented by the gbest $_{\mathrm{d}}$. The rate of 
the velocity for the particle $\mathrm{i}$ is represented as $\mathrm{v}_{\mathrm{i}}=\left(\mathrm{v}_{\mathrm{i} 1}, \mathrm{v}_{\mathrm{i} 2}, \ldots\right.$, $\mathrm{v}_{\text {id }}$ ).

The modified velocity and position of each particle can be calculated using the current velocity and the distance from pbest $_{i d}$ to gbest $_{d}$ as shown in the following formulas:

$$
\begin{gathered}
\mathrm{v}_{\mathrm{id}}{ }^{\mathrm{k}+1}=\mathrm{W} \mathrm{x} \mathrm{v}_{\mathrm{id}}{ }^{\mathrm{k}}+\mathrm{c}_{1 \mathrm{x}} \operatorname{rand}() \mathrm{x}\left(\text { pbest- } \mathrm{x}_{\mathrm{id}}{ }^{\mathrm{k}}\right)+\mathrm{c}_{2} \mathrm{x} \\
\operatorname{rand}\left(\mathrm{x}\left(\mathrm{gbest}_{\mathrm{d}}-\mathrm{X}_{\mathrm{id}}{ }^{\mathrm{k}}\right){ }^{\mathrm{k}+1}=\mathrm{x}_{\mathrm{id}}{ }^{\mathrm{k}}+\mathrm{v}_{\mathrm{id}}{ }^{\mathrm{k}+1}\right. \\
\mathrm{i}=1,2, \ldots \ldots \ldots, \mathrm{N}_{\mathrm{p}}, \mathrm{d}=1,2, \ldots \ldots . . \mathrm{N}_{\mathrm{g}}
\end{gathered}
$$

where, $\mathrm{N}_{\mathrm{P}}$ is the number of particles in a group, $\mathrm{Ng}$ the number of members in a particle, $\mathrm{k}$ the pointer of iterations, $\mathrm{w}$ the inertia weight factor, $\mathrm{C}_{1}, \mathrm{C}_{2}$ the acceleration constant, rand()the uniform random value in the range $[0,1], \mathrm{v}_{\mathrm{i}}{ }^{\mathrm{k}}$ the velocity ofa particle $i$ at iteration $k, v_{d}{ }^{{ }^{m i n}} \leq v_{i d}{ }^{k^{2}} \leq v_{d}{ }^{\max }$ and $x_{i}{ }^{k}$ is the current position of a particle $\mathrm{i}$ at iteration $\mathrm{k}$.In the above procedures, the parameter $\mathrm{v}^{\max }$ determined the resolution, with which regions are to be searched between the present position and the target position.

If $v^{\max }$ is too high, articles might fly past good solutions. If $\mathrm{v}^{\max }$ is too small, particles may not explore sufficiently beyond local solutions. The constants $\mathrm{C}_{1}$ and $\mathrm{C}_{2}$ represent the weighting of the stochastic acceleration terms that pull each particle toward the pbest and gbest positions. Low values allow particle to roam far from the target regions before being tugged back. On the other hand, high values result in abrupt movement toward or past, target regions. Hence, the acceleration constants $\mathrm{C}_{1}$ and $\mathrm{C}_{2}$ were often set to be 2.0 according to past experiences. Suitable selection of inertia weight ' $\mathrm{W}$ ' provides a balance between global and local explorations, thus requiring less iteration on average to find a sufficiently optimal solution.

As originally developed,' w 'often decreases linearly from about 0.3 to -0.2 during a run. In general, the inertia weight $w$ is set according to the following equation:

$$
\mathrm{w}=\mathrm{w}_{\text {max }}-\frac{\mathrm{w}_{\max }-\mathrm{w}_{\min }}{\text { iter }_{\max }} \times \text { iter }
$$

where iter $_{\max }$ is the maximum number of iterations and 'iter' is the current number of iterations.

\section{PSO BASED HYDROTHERMAL SCHEDULING}

Taking the number of particles to be $\mathrm{N}$, the no. of Scheduling intervals as $\mathrm{m}$ and the number of hydro unit, as $\mathrm{N}_{\mathrm{H}}$, each initial trial vector $\mathrm{Q}(\mathrm{j}, \mathrm{m}, \mathrm{p})$ denoting the particles of population to be evolved for $\mathrm{P}=1,2, \ldots \mathrm{N}$ is selected. The discharge of $\mathrm{j}^{\text {th }}$ hydro plant at $\mathrm{m}^{\text {th }}$ interval is randomly generated as $\mathrm{Q}_{\mathrm{GHjm}} \sim \mathrm{U}\left(\mathrm{Q}_{\mathrm{GHj}}{ }^{\min }, \mathrm{Q}_{\mathrm{GHj}}{ }^{\max }\right)$

Let $\mathrm{P}_{\mathrm{K}}=\left[\mathrm{P}_{\mathrm{GT} 1}, \mathrm{P}_{\mathrm{GT} 2}, \ldots . \mathrm{P}_{\mathrm{GTi}}, \ldots . . \mathrm{PG}_{\mathrm{TNT}}, \mathrm{Q}_{\mathrm{GH}}, \mathrm{Q}_{\mathrm{GH} 1}, \mathrm{Q}_{\mathrm{GH} 2}\right.$, $\left.\ldots \mathrm{Q}_{\mathrm{GHj}} \ldots, \mathrm{Q}_{\mathrm{GHNH}}\right]^{\mathrm{T}}$ be a trail matrix designating the $\mathrm{K}^{\mathrm{th}}$ individual of population to be evolved and

$$
\begin{gathered}
P_{\mathrm{GTi}}=\left[\mathrm{P}_{\mathrm{GTi} 1}, \mathrm{P}_{\mathrm{GTi} 2}, \ldots \mathrm{P}_{\mathrm{GTim}}, \ldots \mathrm{P}_{\mathrm{GTiM}}\right], \\
\mathrm{Q}_{\mathrm{GHj}}=\left[\mathrm{Q}_{\mathrm{GHj}}, \mathrm{Q}_{\mathrm{GH} 2}, \ldots \mathrm{Q}_{\mathrm{GHj}}, \ldots . \mathrm{Q}_{\mathrm{GHjM}}\right]
\end{gathered}
$$

The elements $P_{\mathrm{GTim}}$ and $\mathrm{Q}_{\mathrm{GHjm}}$ are the power output of the $\mathrm{i}^{\text {th }}$ thermal unit and the discharge rate of the $\mathrm{j}^{\text {th }}$ hydro plant at time interval $\mathrm{m}$. The range of elements $\mathrm{P}_{\mathrm{GTim}}$ and $\mathrm{Q}_{\mathrm{GHjm}}$ should satisfy the thermal generating capacity and the water discharge rate constraints in equations (3) and (7) respectively.

Assuming the spillage in Eq (9) to be zero for simplicity the hydraulic continuity constraints are

$$
\begin{gathered}
\mathrm{V}_{\mathrm{Hjo}}-\mathrm{V}_{\mathrm{HjM}}=\sum_{\mathrm{m}=1}^{\mathrm{M}} \mathrm{Q}_{\mathrm{GHjm}}-\sum_{\mathrm{m}=1}^{\mathrm{M}} \sum_{\mathrm{l}=1}^{\mathrm{R}_{\mathrm{uj}}} \mathrm{Q}_{\mathrm{GH}}\left(\mathrm{m}-\tau_{\mathrm{ij}}\right) \\
\quad \sum_{\mathrm{m}=1} \mathrm{I}_{\mathrm{Hjm}}, \mathrm{j} \in \mathrm{N}_{\mathrm{H}}
\end{gathered}
$$

To meet exactly the restrictions on the initial and final reservoir storage in eq.(9), the water discharge rate of $\mathrm{j}^{\text {th }}$ hydro plant in the dependent interval ' $\mathrm{d}$ ' is then calculated by

$$
\begin{aligned}
\mathrm{Q}_{\mathrm{GHjd}} & =\mathrm{V}_{\mathrm{Hjo}}-\mathrm{V}_{\mathrm{HjM}}+\sum_{\mathrm{m}=1}^{\mathrm{M}} \mathrm{I}_{\mathrm{Hjm}}+ \\
& \sum_{\mathrm{m}=1}^{\mathrm{M}} \sum_{\mathrm{l}=1}^{\mathrm{R}_{\mathrm{uj}}} \mathrm{Q}_{\mathrm{GHI}}\left(\mathrm{m}-\tau_{\mathrm{ij}}\right)-\sum_{\mathrm{m}=1}^{\mathrm{M}} \mathrm{Q}_{\mathrm{GHj}}, \mathrm{j} \in \mathrm{N}_{\mathrm{H}}
\end{aligned}
$$

The dependent water discharge rate must satisfy the constraints is Eq (7).After knowing the water discharges, the reservoir volumes of different intervals are determined. Then, the hydro generations are calculated from Eq (11). Knowing the calculated hydro generations, $\mathrm{P}_{\mathrm{GHjm}}$ and the given load demand $\mathrm{P}_{\mathrm{Djm}}$ for $\mathrm{m}=1,2 \ldots . . \mathrm{m}$, thermal generations $\mathrm{P}_{\mathrm{GTi}}$ can be calculated as

$\mathrm{P}_{\mathrm{GTim}}=\mathrm{P}_{\text {Dm }}+\mathrm{P}_{\text {Lossm }}-\sum_{\mathrm{j}=1}^{\mathrm{N}_{\mathrm{H}}} \mathrm{P}_{\mathrm{GHm}}$

Also to meet exactly the power balance constraints in Eq (3), the thermal power generation $\mathrm{P}_{\mathrm{GTdm}}$ of the dependent thermal generating unit can then be calculated using the following equation.

$$
\mathrm{P}_{\mathrm{GTdm}}=\mathrm{P}_{\mathrm{Dm}}-\sum_{\substack{\mathrm{i}=1 \\ \mathrm{i} \neq \mathrm{d}}}^{N_{G T}}-\sum_{\substack{\mathrm{j}=1 \\ \mathrm{P}_{\mathrm{GHm}}}}^{\mathrm{N}_{\mathrm{H}}}
$$

The dependent thermal generation must satisfy the constraints in Eq. (4).All the generation levels, discharges, reservoir water volumes and initial and final reservoir storage volumes must be checked against their limiting values as per eq's.(4)-(11).

\section{Stopping Rule :}

The iterative procedure of generating new solutions with minimum function value is terminated when a predefined maximum number of iterations (generations) is reacted. 


\section{PSO ALGORITHM}

The computational process of PSO technique can be described in the following steps.

Step 1 Input parameters of the system and specify the upper and lower boundaries of each variable.

Step 2 Initialize randomly the particles of the population according to the limit of each unit including individual dimensions, searching points and velocities. There initial particles must be feasible candidate solutions that satisfy the practical operating constraints.

Step 3 Let, $Q p=\left[q_{11}, q_{12}, \ldots . ., q_{1 m}, q_{21}, q_{22}, \ldots\right.$. $\left.\mathrm{q}_{2 \mathrm{~m}}, \ldots \mathrm{q}_{\mathrm{n} 1}, \mathrm{q}_{\mathrm{n} 2}, \ldots, \mathrm{q}_{\mathrm{nm}}\right]$, be the trait vector denoting the particles of population to be evolved. The elements of $\mathrm{q}_{\mathrm{jm}}$ are the discharges of turbines of reservoirs at various intervals subjected to their capacity constraints in (7). $\mathrm{q}_{\mathrm{id}}$, be the dependent discharge of $i_{\text {th }}$ hydro plant at $\mathrm{d}_{\mathrm{th}}$ interval is randomly selected from among the committed ' $\mathrm{m}$ ' intervals. Then, knowing the hydro discharges, storage volumes of reservoirs $\mathrm{V}_{\mathrm{jm}}$ are calculated by (9). Then $\mathrm{P}_{\mathrm{GHjm}}$ is calculated from (11) for all the intervals.

Step 4 Compare each particle (4 x 24) evaluation value with its $\mathrm{P}_{\text {best }}$ the best evaluations value among $\mathrm{P}_{\text {best }}$ is denoted as $\mathrm{g}_{\text {best }}$.

Step 5 Update the iteration as $\mathrm{K}=\mathrm{K}+1$; inertia weight, velocity\& position by (12-14).

Step 6 Each particle is evaluated according to its updated position, only when satisfied by all constraints. If the evaluation value of each particle is better than the previous $\mathrm{P}_{\text {best }}$. The current value is set to be $P_{\text {best }}$.

If the best $P_{\text {best }}$ is better than $g_{\text {best }}$, the value is set to be $g_{\text {best }}$.

Step 7 If the stopping criterion is reacted, then go to Step-8, otherwise go to Step-2.

Step 8 The individual that generates the latest $g_{\text {best }}$ is the solution of the problem and then print the result and stop.

\section{NUMERICAL RESULTS}

\section{A. Test System}

To verify the applicability and to evaluate the performance of the proposed PSO algorithm, a test system has been adapted from [22], [23]. It consists of a multi chain cascade of four hydro units, and a number of thermal units represented by an equivalent thermal plant. The schedule horizon is one day with 24 intervals of 1 hour each.

The cost of thermal generation can be obtained in two ways:

a) By using a standard economic dispatch technique to find the optimal operation cost of the on-line thermal generators. b) By assuming the thermal generation is represented by an equivalent single plant, where characteristic can be determined as described in [1].

The hydraulic Sub-system is characterized by the following:

c) A multi chain cascade flow network, with all of the plants on one stream;

d) Reservoir transport delay between successive reservoirs;

e) Variable head hydro plants;

f) Variable natural inflow rates into each reservoir;

g) Variable load demand over scheduling period.

The data of the test system considered here are the same as in [10] and the additional data with valve point loading effect are also same as in Reference[11].

The hydro Sub-system configuration is shown in fig 1.

The hydraulic test network models most of the complexities encountered in practical hydro networks. The load demand, hydro units power generation Coefficients, river inflows, reservoir limits are given in reference [11].

The fuel cost function of the equivalent thermal plant unit with valve point loading is

$$
\begin{array}{r}
\mathrm{C}_{\mathrm{i}}\left(\mathrm{P}_{\mathrm{GTi}}\right)=5000+19.2 \mathrm{P}_{\mathrm{GTi}}+0.002 \mathrm{P}_{\mathrm{G} 2 \mathrm{Ti}}+\mid 700 \mathrm{Sin}(0.085 \\
\left(\mathrm{P}_{\mathrm{GTi}}{ }^{\text {min }}-\mathrm{P}_{\mathrm{GTi}}\right) \mid
\end{array}
$$

And the inequality constraint limit of this unit is

$$
500_{(\mathrm{MW})} \leq \mathrm{P}_{\mathrm{GTi}} \leq 2500_{(\mathrm{MW})}
$$

The Spillage rate for the hydraulic system is not taken into account for simplicity and further the electric loss from the hydro plant to the load is taken to be negligibly small.

To demonstrate the effectiveness of the proposed PSO method, the system is considered with prohibited discharge zones and with valve point loading effects.

\section{B. Simulation Results}

In short term hydrothermal scheduling problem, the two important parameters, that can be allowed to vary, are the satisfaction of the final reservoir levels and the cost of thermal generation. The present work has been implemented in command line of Matlab-7.0 for the solution of hydrothermal scheduling. The program was run on a $2.70 \mathrm{GHz}$, Pentium-® Dual core, with 1GB RAM PC. After a number of trails of run with different values of PSO parameters tuning, such as inertia weight, number of particles, maximum allowable velocity, the details of key parameters selected are: $\mathrm{w}_{\max }=0.9, \mathrm{w}_{\min }=0.4, \mathrm{~N}=20, \mathrm{c}_{1}=\mathrm{c}_{2}=2.0$, iter $_{\max }=100$.

The optimal hydro generations, optimal hydro discharges, hydro reservoir levels with minimum cost obtained by the proposed PSO methods are reported in tables 6-8 respectively. 


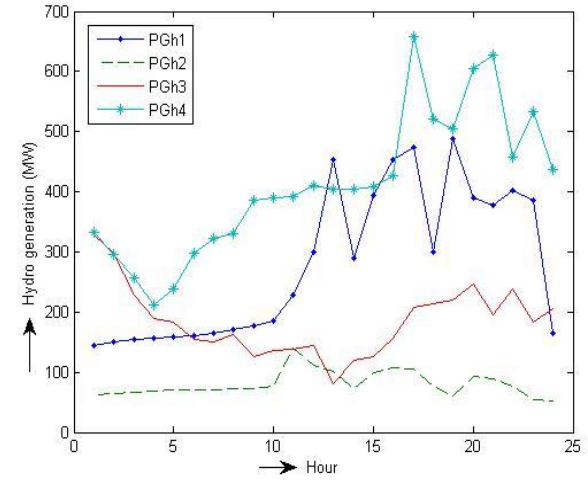

Fig.2 Hourly Hydro plant Power Generations

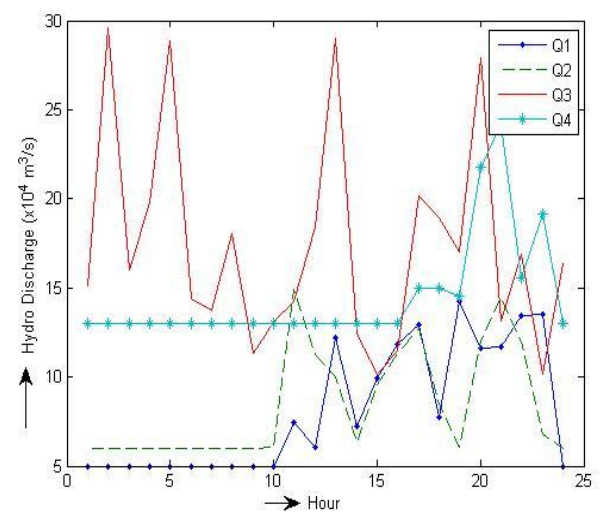

Fig.3 Hydro plant Discharge

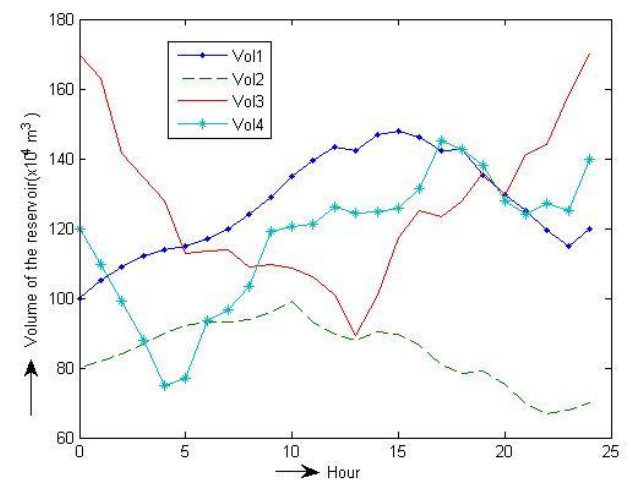

Fig.4 Hydro Reservoir Storage Volumes.
TABLE: 2 HOURLY PLANT DisCHARGES $\left(\times 10^{4} \mathrm{M}^{3}\right)$

\begin{tabular}{|c|c|c|c|c|}
\hline Hour & Q1 & Q2 & Q3 & Q4 \\
\hline 1 & 5.0000 & 6.0000 & 20.0855 & 13.0000 \\
\hline 2 & 5.0000 & 6.0000 & 14.8462 & 13.0000 \\
\hline 3 & 5.0000 & 6.0000 & 14.5574 & 13.0000 \\
\hline 4 & 5.0000 & 6.0000 & 29.9338 & 13.0000 \\
\hline 5 & 5.0000 & 6.0000 & 19.7629 & 13.0000 \\
\hline 6 & 5.0000 & 6.0000 & 19.5213 & 13.0000 \\
\hline 7 & 5.0000 & 11.1817 & 13.9664 & 13.0000 \\
\hline 8 & 5.0000 & 8.5639 & 21.9058 & 13.0000 \\
\hline 9 & 5.0000 & 11.6833 & 10.6531 & 13.0000 \\
\hline 10 & 11.6845 & 11.1089 & 14.8067 & 13.0000 \\
\hline 11 & 9.7279 & 10.0058 & 19.9333 & 13.0000 \\
\hline 12 & 9.9741 & 10.3444 & 15.4261 & 13.0000 \\
\hline 13 & 11.7367 & 8.4407 & 14.2368 & 13.0000 \\
\hline 14 & 6.7460 & 11.6675 & 15.6500 & 13.0000 \\
\hline 15 & 14.0606 & 6.1333 & 14.0058 & 13.0000 \\
\hline 16 & 6.4655 & 11.7517 & 19.5437 & 13.0000 \\
\hline 17 & 10.3722 & 8.9621 & 11.0288 & 13.0000 \\
\hline 18 & 11.8711 & 8.9506 & 11.4574 & 13.0000 \\
\hline 19 & 14.7748 & 10.8394 & 28.1152 & 15.7367 \\
\hline 20 & 13.4112 & 6.6569 & 28.3459 & 13.0041 \\
\hline 21 & 6.3168 & 8.4911 & 15.4668 & 22.2915 \\
\hline 22 & 10.5628 & 6.5219 & 18.7661 & 23.0842 \\
\hline 23 & 7.2958 & 8.6968 & 12.7706 & 23.4654 \\
\hline 24 & 5.0000 & 6.0000 & 21.0000 & 13.0000 \\
\hline
\end{tabular}


TABLE: 1 Hydro THERMAL POWER GENERATIONS AND OPERATING COST OF EQUIVALENT THERMAL UNIT.

\begin{tabular}{|c|c|c|c|c|c|c|c|c|}
\hline Hour & Hydro1 & Hydro2 & Hydro3 & Hydro4 & Equivalent Thermal & Operating Cost & Loss & Demand \\
\hline 1 & 143.8144 & 61.8151 & 321.2825 & 332.7922 & 510.2957 & 14804.9367 & 0.0000 & 1370.0000 \\
\hline 2 & 149.4909 & 63.5051 & 246.4740 & 296.0982 & 634.4318 & 18665.8623 & 0.0000 & 1390.0000 \\
\hline 3 & 153.7395 & 66.0341 & 231.7937 & 256.5596 & 651.8732 & 18649.0470 & 0.0000 & 1360.0000 \\
\hline 4 & 156.5676 & 68.5559 & 270.9775 & 211.3765 & 582.5224 & 16643.8241 & 0.0000 & 1290.0000 \\
\hline 5 & 157.9804 & 70.2331 & 222.8005 & 236.0156 & 602.9704 & 16655.0631 & 0.0000 & 1290.0000 \\
\hline 6 & 160.8036 & 71.0705 & 209.2636 & 242.4304 & 726.4318 & 20472.3135 & 0.0000 & 1410.0000 \\
\hline 7 & 165.0319 & 108.7630 & 172.6008 & 247.8405 & 955.7637 & 25839.2282 & 0.0000 & 1650.0000 \\
\hline 8 & 170.6580 & 87.6200 & 192.4158 & 306.5693 & 1242.7369 & 31761.7471 & 0.0000 & 2000.0000 \\
\hline 10 & 387.8581 & 96.4377 & 168.7674 & 352.5204 & 1314.4164 & 33180.3073 & 0.0000 & 2320.0000 \\
\hline 11 & 336.3422 & 88.5497 & 182.2171 & 355.8591 & 1267.0319 & 33234.1502 & 0.0000 & 2230.0000 \\
\hline 12 & 344.0508 & 87.0328 & 182.7510 & 386.6004 & 1309.5650 & 32919.0708 & 0.0000 & 2310.0000 \\
\hline 13 & 394.6999 & 75.0250 & 194.3870 & 378.5038 & 1187.3842 & 31317.4820 & 0.0000 & 2230.0000 \\
\hline 14 & 248.5863 & 88.4380 & 223.0302 & 384.7371 & 1255.2084 & 32716.0318 & 0.0000 & 2200.0000 \\
\hline 15 & 469.3308 & 58.5306 & 227.5507 & 408.6391 & 965.9489 & 25699.8086 & 0.0000 & 2130.0000 \\
\hline 16 & 239.6118 & 87.2711 & 279.7513 & 416.9959 & 1046.3699 & 27468.6170 & 0.0000 & 2070.0000 \\
\hline 17 & 367.1793 & 71.1986 & 209.9862 & 421.2548 & 1060.3812 & 27083.0721 & 0.0000 & 2130.0000 \\
\hline 19 & 447.9425 & 69.5130 & 389.0751 & 501.1761 & 832.2933 & 21670.4962 & 0.0000 & 2240.0000 \\
\hline 20 & 384.6560 & 51.9737 & 364.7770 & 447.0443 & 1031.5490 & 27629.5083 & 0.0000 & 2280.0000 \\
\hline 21 & 198.8359 & 62.5183 & 279.2299 & 638.0259 & 1061.3901 & 27071.1105 & 0.0000 & 2240.0000 \\
\hline 22 & 308.8412 & 53.9597 & 340.2419 & 583.4025 & 833.5546 & 21694.0029 & 0.0000 & 2120.0000 \\
\hline 23 & 225.5577 & 65.7688 & 255.4101 & 619.4911 & 683.7723 & 18472.1612 & 0.0000 & 1850.0000 \\
\hline 24 & 165.0319 & 51.6079 & 364.9660 & 436.9659 & 571.4283 & 17001.5918 & 0.0000 & 1590.0000 \\
\hline
\end{tabular}


TABLE: 3 HOURLY STORAGE VOLUME OF HYDRO RESERVOIRS $\left(\mathrm{X} 10^{4} \mathrm{M}^{3}\right)$

\begin{tabular}{|c|c|c|c|c|}
\hline Hour & Vol1 & Vol2 & Vol3 & Vol4 \\
\hline 0 & 100.0000 & 80.0000 & 170.0000 & 120.0000 \\
\hline 1 & 105.0000 & 82.0000 & 158.0145 & 109.8000 \\
\hline 2 & 109.0000 & 84.0000 & 151.3683 & 99.2000 \\
\hline 3 & 112.0000 & 87.0000 & 145.8109 & 87.8000 \\
\hline 4 & 114.0000 & 90.0000 & 128.8771 & 74.8000 \\
\hline 5 & 115.0000 & 92.0000 & 123.1142 & 81.8855 \\
\hline 6 & 117.0000 & 93.0000 & 118.5929 & 83.7317 \\
\hline 7 & 120.0000 & 87.8183 & 118.6265 & 85.2891 \\
\hline 8 & 124.0000 & 86.2544 & 109.7208 & 102.2229 \\
\hline 9 & 129.0000 & 82.5711 & 111.0677 & 108.9858 \\
\hline 10 & 128.3155 & 80.4622 & 113.4427 & 115.5071 \\
\hline 11 & 130.5876 & 79.4564 & 108.0733 & 116.4735 \\
\hline 12 & 130.6135 & 77.1120 & 118.0151 & 125.3792 \\
\hline 13 & 129.8768 & 76.6713 & 128.6151 & 123.0323 \\
\hline 14 & 135.1308 & 74.0038 & 135.9449 & 124.8390 \\
\hline 15 & 132.0702 & 76.8705 & 147.0202 & 131.7723 \\
\hline 16 & 135.6047 & 73.1188 & 144.6632 & 134.1984 \\
\hline 17 & 134.2325 & 71.1567 & 161.3625 & 135.4352 \\
\hline 18 & 130.3614 & 68.2061 & 164.5039 & 138.0852 \\
\hline 19 & 122.5866 & 64.3667 & 159.5126 & 136.3543 \\
\hline 20 & 115.1754 & 65.7098 & 152.9999 & 142.8939 \\
\hline 21 & 115.8586 & 66.2187 & 163.2585 & 131.6312 \\
\hline 22 & 113.2958 & 68.6968 & 170.7429 & 120.0043 \\
\hline 23 & 115.0000 & 68.0000 & 171.9461 & 124.6541 \\
\hline 24 & 120.0000 & 70.0000 & 170.0000 & 140.0000 \\
\hline
\end{tabular}

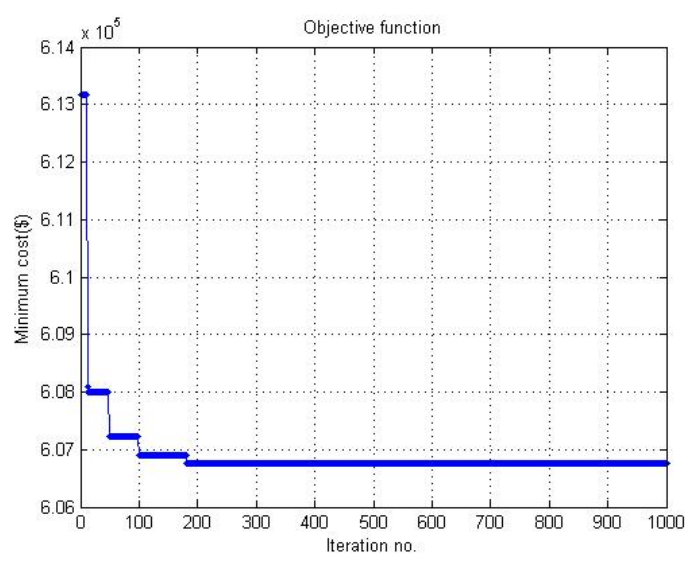

Fig.5 Convergence characteristic of PSO Algorithm for the test case.
TABLE: 4 SUMMARY OF TEST RESULTS

\begin{tabular}{|l|l|l|l|l|}
\hline \multirow{3}{*}{ Method } & \multicolumn{2}{|c|}{$\begin{array}{l}\text { Operating cost of equivalent } \\
\text { thermal unit (in \$) }\end{array}$} & \multicolumn{2}{c|}{ Execution time(in sec) } \\
\cline { 2 - 5 } & $\begin{array}{l}\text { Without } \\
\text { Prohibited } \\
\text { Discharge } \\
\text { Zones }\end{array}$ & $\begin{array}{l}\text { With } \\
\text { Prohibited } \\
\text { Discharge } \\
\text { Zones }\end{array}$ & $\begin{array}{l}\text { Without } \\
\text { Prohibited } \\
\text { Discharge } \\
\text { Zones }\end{array}$ & $\begin{array}{l}\text { With } \\
\text { Prohibited } \\
\text { Discharge } \\
\text { Zones }\end{array}$ \\
\hline \multirow{3}{*}{ PSO } & 602255.525216 & $\begin{array}{l}606758.57262 \\
3\end{array}$ & 111.91608 & 122.18241 \\
& & & 2 & 0 \\
\hline & & 607154.56166 & 398.33378 & 422.21354 \\
GA & 606958.862515 & 3 & 5 & 1 \\
\hline
\end{tabular}

VIII. CONCLUSION

In this paper an approach of particle swarm optimization has been proposed and demonstrated to solve short - term hydrothermal scheduling problem. In the algorithm, the thermal generator units are represented by and equivalent unit. The generator load power balance equations and total water discharge equation have been subsumed into system model .constraints on the operational limits of the thermal and hydro units on the reservoir volume limits are also included in the algorithm. the numerical results show that the proposed approach is better than generic algorithm in terms of having better solution quality and good convergence characteristics. The PSO approach can easily be extended to other complex optimization problems faced by the utilities.

\section{REFERENCES}

[1]. A.J.Wood, B.F.Wollenberg, "Power Generation Operation and Control", John Wileyand Sons, New York, 1984

[2]. M.F. Carvalloh, S.Soares, "An efficient hydrothermal scheduling algorithm”, IEEE Trans. PWRS 4 (1987) 537-542.

[3]. L.Engles, R.E. Larson, J.Peschon, K.N. Stanon, "Dynaming programming applied to hydro and thermal generation scheduling", in: IEEE tutorial course text, 76CH1 107-2-PWR, IEEE, New York, 1976.

[4]. S.chang, C.Cen, L.fung, P.B.Luh, "Hydroelectric Generation Scheduling With An Effective Differential Dynamic Programming", IEEE Trans. Power syst. 5(1990) 737-743

[5]. Q. Xia, N.Xiang, S.Wang, B.Zang, M.Huang, "Optimal Daily Scheduling Of Cascaded Plants Using A New Algorithm Of Nonlinear Minimum Cost Network Flow", IEEE Trans. Power syst. 3(3) (1988) 929-935

[6]. K.P. Wong, Y.W. Wong, "Short Term Hydrothermal Scheduling": part 1. Simulated annealing approach, IEE Proc. C 141 (1994) 497-501

[7]. Y.-G. Wu, C,=Y. Ho, D.-Y. Wang, "A diploid genetic approach to shortterm scheduling of hydrothermal systems", IEEE Trans. Power syst. 15(November (5)) (2000) 1268-1274

[8]. S.O. Orero, M.R. Irving, "A genetic algorithm modeling framework and solution technique for short-term optimal hydrothermal scheduling", IEEE Trans. Power Syst. 13(2) (1998) 501-518

[9]. P.-H Chen, H.-C. Chang, "Genetic added scheduling of hydraulically coupled plants in hydro-thermal coordination", IEEE Trans. Power syst. 11 (may(2)) (1996) 975-981.

[10]. P.K. Hota, R. Chakrabarti, P.K. Chattopadhyay, "Short-term hydrothermal scheduling through evolutionary technique", EPSR 52 (November (2)) (1999) 189-196

[11]. N. Sinha, R.Chakrabarti, P.K. Chattopadhyay, "Fast evolutionary technique for short-term hydrothermal scheduling", IEEE Trans. Power syst. 18(1) (2003) 214-220. 
[12]. K.K. Mandal*, M.Basu, N.Chakraborty, "Particle Swarm Optimization technique based short-term hydrothermal Scheduling", Appled soft computing 8(2008) 1392-1399

[13]. Chandrasekar Samudi, GauthamP.Das, Piyush C. Ojha,Sreeni. T.S, 9781-4244-1904-3/08/ 2008 IEEE

[14]. Wang, C., Shahidehpour, S.M., "Power generation Scheduling for multi- area hydrothermal power systems with tie-line constraints", cascaded reservoirs and uncertain data.", IEEE Trans. PWRS, Vol. 8, No. 3, 1993, pp. 1333-1340

[15]. Soares, S., Lyra, C., Tavayes, WO., "Optimal generation scheduling of hydrothermal power system.”, IEEE Trans. PAS Vol. 99, No 3, 1980 1106-1114.

[16]. B.Yu, X. Yuan, J.Wang, "Short-term hydro-thermal scheduling using Particle swarm optimization method", Energy convers. Manage.48 (2007) 1902-1908.

[17]. Z.L., Gaing, "Particle swarm optimization to solving the economic dispatch considering the generator constraints", IEEE Trans. 18 (August(3)) (2003)1187-1195.

[18]. J.B. Park, K.S. Lee, J.R. Shin, K.Y. Lee, “A particle swarm optimization for economic dispatch with non-smooth cost functions", IEEE Trans. Power Syst. 20 (1) (2005) 34-42

[19]. K.Price, R,Storn, "Differential evolution: numerical optimization made easy". Dr. Dobbs J.22(4) (1997) 18-24

[20]. K.K. Mandal*, M.Basu, N.Charaborty, "Particle Swarm Optimization technique based short-term hydrothermal Scheduling", Appled soft computing 8(2008) 1392-1399

[21]. Chandrasekar Samudi, Gautham P.Das, Piyush C. Ojha,Sreeni. T.S "Hydrothermal Scheduling Using Particle Swarm Optimization, 978-14244-1904-3/08/ 2008 IEEE.

[22]. Wang, C., Shahidehpour, S.M., "Power generation Scheduling for multi- area hydrothermal power systems with tie-line constraints, cascaded reservoirs and uncertain data.", IEEE Trans. PWRS, Vol. 8, No. 3, 1993, pp. 1333-1340

[23]. Soares, S., Lyra, C., Tavayes, WO., "Optimal generation scheduling of hydrothermal power system.”, IEEE Trans. PAS Vol. 99, No 3, 1980 1106-1114.

[24]. B.Yu, X. Yuan, J.Wang, "Short-term hydro-thermal scheduling using Particle swarm optimization method", Energy convers. Manage.48 (2007) 1902-1908.

\section{AUTHORS PROFILE}

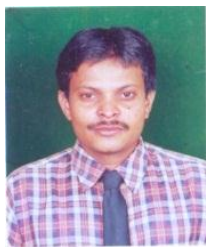

G.Sreenivasan received his graduation in 1996, Masters in 2001 from JNT University college of engineering, Anantapur and pursuing Ph.D at JNT University, Kakinada. Presently he is working as Associate Professor in the Department of Electrical and Electronics Engineering, Intell Engineering College, Anantapur since 2001. His area of interest is applications of GA and PSO to Power System Operation and Control. He has published research papers in 1 international and 2 national journals and has publications in national and international conferences. $\mathrm{He}$ has participated several workshops conducted by various engineering colleges at south India. Recently he co-authored the text book, "Power System Operation and Control" under the publication of Pearson Education, New Delhi. He is the life member of ISTE and IE.

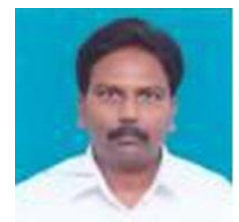

Dr. CH. SaiBabu received his graduation from Andhra university and Masters from REC, Warangal and Ph.D from JNTU,Hyd. He is the Professor in the Department of Electrical and Electronics Engineering and working as Director of Energy Management and Empowerment at JNT University, Kakinada. He has about 10 publications in international journals and 44 national and international conferences. He authored a text book, "Elements of Power Electronics" published by S.Chand and Co. He is the member of AICTE team and Member of governing council for various affiliated engineering colleges of JNTU, Kakinada.

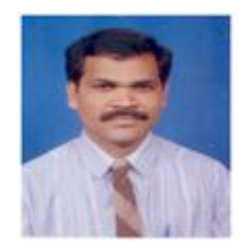

Dr. S.Sivanagaraju received his graduation in 1998, Masters in 2000 from IIT, Kharagpur and his Ph.D from JNT University, Hyderabad in 2004. He is working as Professor in the Department of Electrical and Electronics Engineering JNT University, Kakinada, Andhra Pradesh since 1992. He has received 2 National awards (Panditmadan Mohan malaviya Memorial prize award and Best paper prize award) form the Institute of Engineers (India) for the year 2003 - 2004. He is also a referee for the IEEE proceedings - generation, transmission and distribution and international journal of emerging electric power systems. He has about 50 publications in national and international journals and conferences to his credit. His areas of interest are in Distribution Automation, Genetic Algorithm Applications to Distribution Systems and Power Systems. 